\title{
Impact of Leadership of Trained Intensivist in Pediatric Intensive Care Unit in a Middle Income Country: An Uncontrolled Before-After Study
}

\author{
Selman Kesici ${ }^{1} \cdot$ Benan Bayrakci ${ }^{2}$
}

Received: 2 July 2019 / Accepted: 4 December 2019 / Published online: 10 January 2020

(C) Dr. K C Chaudhuri Foundation 2019

\begin{abstract}
Objective To evaluate the effects generated by an intensivist in pediatric intensive care unit (PICU) on the process of care and patient outcomes.

Methods This study was a retrospective observational study conducted in the 16-bedded PICU of a tertiary referral center. Two years (2013-2015) period of the PICU without an intensivist and the following two years (2015-2017) when it was attended by an intensivist who was also the first ever graduate of the fellowship program in Turkey were compared.

Results Number of patients followed in PICU increased more than 2-fold. Number of mechanically ventilated patients increased more than 2 -folds and presence of intensivist reduced the mechanical ventilation duration by $59 \%$. Presence of intensivist reduced the mortality rates by 2.18 times. It was shown that management of PICU beds by an intensivist resulted in increased number of patients per year per PICU bed, increased care of true critical care patients who are in need of more intensive therapies and invasive procedures including extracorporeal treatment options, decreased length of stay, decreased number and rate of nosocomial infections, and decreased mortality rate.

Conclusions What transforms a unit full of critically ill patients to an intensive care unit is a dedicated intensivist. The current study demonstrated that intensivist is the crucial component of the PICUs.
\end{abstract}

Keywords Intensivist $\cdot$ Pediatric intensive care unit $\cdot$ Outcome

\section{Introduction}

There are several studies indicating that presence of pediatric intensivist improves the quality of care in pediatric intensive care units (PICUs) [1, 2]. In high-income countries, PICU being attended by a pediatric intensivist is not a matter of debate. In those countries, favorable impact of $24 \mathrm{~h}$ inhospital presence of a PICU attending physician had been demonstrated $[3,4]$. In Turkey, before the graduation of pioneer PICU fellows, only $30 \%$ of the PICUs were attended by pediatric intensivists [5]. In high-income countries, organization of PICUs were completed $30 \mathrm{y}$ ago and many studies

Selman Kesici

selmankesici@hotmail.com

1 Department of Pediatric Intensive Care Unit, Hacettepe University İhsan Doğramacı Children's Hospital, Ankara, Turkey

2 Department of Pediatric Intensive Care Unit, Hacettepe University İhsan Doğramacı Children's Hospital, Ankara, Turkey about the quality of care were conducted since then. In Turkey, PICU fellowship program was initiated at 2011. First fellows graduated at the end of 2014. In Turkey, doctors in every specialty are obliged to serve in state hospitals for a predefined time period. For this reason the first graduate of the PICU fellowship program was appointed to a hospital of Ministry of Health. There had been no PICU specialists in that hospital previously and this situation allowed authors to measure how the presence of an intensivist affected the quality of care in a PICU.

In this study authors evaluated the effect of pediatric intensivist on the process of care and PICU outcomes.

\section{Material and Methods}

This study is an observational study with a retrospective cohort conducted in the 16-bed PICU of the Dr. Sami Ulus Children's Hospital in Ankara-Turkey, which is a tertiary referral center with 400 pediatric beds. This hospital includes a pediatric residency program and pediatric subspecialty 
fellowship programs. Pediatrics residency program has 80 residents and lasts $4 \mathrm{y}$ as in all residency programs in Turkey.

PICU admissions from January 2013 through January 2017 were included in the study. Two years (2013-2015) period of the PICU without an intensivist and the following two years (2015-2017) period when it was attended by an intensivist are compared. Before the arrival of a pediatric intensivist the PICU had been managed by a general pediatrician who was attending the PICU within the working hours. Four pediatric residents [three of them at their second postgraduate year (PGY-2) and one of them as senior (PGY-3)] accompanied during daytime. PGY-2 residents were on duty every three days. At nighttime, PGY-2 resident on duty was responsible for the patient care in PICU and was supervised by a PGY-3 or PGY-4 resident, who was in-charge of the other pediatric wards also. PICU admission decisions were given by the senior residents (PGY-3 or PGY-4) on duty and they were responsible for stabilizing the critically ill patients during their initial admission to PICU.

Before the arrival of pediatric intensivist post-operative cardiac patients were managed in the cardiac-PICU which was directed by the cardiac surgeons.

During the entire study period there were a total number of 32 nurses for 16 beds in the PICU and patient per nurse ratio was 2 during shifts. Although, $30 \%$ of the nurses have stopped working in the PICU during the study period, the number of nurses was kept constant at 32 with new appointments. Personnel staffing and structure of the PICU remained stable throughout the study period.

On January 1st, 2015 the first ever graduate of the PICU fellowship program started practice and was appointed as the intensivist in-charge of the PICU. Pediatric intensivist was responsible for all of the admissions and discharges. He directly participated in acute interventions. PICU team, including residents and nurses, started rounding minimum twice a day under the leadership of the pediatric intensivist. Senior residents covering all wards of the hospital participated in the evening PICU rounds in order to be kept updated for patients in the PICU. Education programs for residents and nurses were developed and meticulously implemented. Pediatric intensivist was on call for $24 \mathrm{~h} /$ day, and remained available for any acute changes in patients, new admissions or need for revised plans in ongoing treatments. Pediatric intensivist was consulted for all new unstable admissions and acute worsening of PICU patients. All central venous catheter implementations were carried out and all laboratory results were reviewed by the pediatric intensivist with the accompanying PGY-2 resident on duty.

Upon starting working, cardiac-PICU was also consulted by the pediatric intensivist and patients who were not extubated in the early post-operative period and patients requiring prolonged medical follow-up were transferred to the PICU.
Number of admissions, center where the patients were transferred from, mean age of the patients, gender, PRISMIII scores, length of stay, number of mechanically ventilated patients, mean mechanical ventilator duration, number of patients that underwent tracheotomy, mean mechanical ventilator duration before tracheotomy, number of implemented central venous catheters, and number of patients on dialysis, plasma exchange and ECMO applications, nosocomial infections, crude and standard mortality rate (SMR) were recorded and compared between the pre and post pediatric intensivist periods [6].

Mortality rate, SMR, number of admissions, length of stay, mechanical ventilator duration and number of nosocomial infections were compared between the two periods as primary outcome measures.

Data were analyzed using the SPSS version 21.0 software program (Statistical Package for Social Sciences v.21, IBM, Chicago, IL). Pearson Chi-Square test was used to investigate the association between categorical variables. The Student $t$ test was used to compare continuous numerical variables between groups. General linear model was performed to predict the effect of intensivist on the length of stay in PICU, mechanical ventilator duration and mechanical ventilator duration prior to tracheotomy. To predict the effect of intensivist on the mortality rate, binary logistic regression was used. Institutional Ethics Committee approved the study.

\section{Results}

A total of 1787 patients were admitted to the PICU during the study period. Five hundred thirteen of them $(28.7 \%)$ were admitted during the pre-pediatric intensivist period and 1274 of them $(71.3 \%)$ were admitted during the post-pediatric intensivist period. Characteristics of patients, treatment options, number of infections and PICU outcome of the two periods are shown in Table 1.

Admission to PICU was directed from national emergency call service (112), inpatient units and among post-surgical patients. In the pre-pediatric intensivist period, 227 patients (44.2\%) were transferred to PICU via emergency ambulance service; 275 (53.6\%) patients were transferred from inpatient units and $11(2.1 \%)$ post-surgical patients were admitted to the PICU. In post- pediatric intensivist period, 736 patients (57.7\%) were transferred to the PICU via emergency ambulance service, $366(28.7 \%)$ patients were transferred from inpatient units and $172(13.5 \%)$ post-surgical patients were admitted to the PICU (Table 1).

A logistic regression analysis was performed to ascertain the effects of presence of intensivist on the likelihood of mortality. The logistic regression model was statistically significant, $(p<0.001)$. The model explained $26.0 \%$ (Nagelkerke $\mathrm{R}^{2}$ ) of the variance in the mortality. Presence of intensivist 
Table 1 Comparison of two periods, in terms of patient characteristics, treatment options and PICU outcome

\begin{tabular}{|c|c|c|c|}
\hline & $\begin{array}{l}\text { Pre-intensivist period } \\
(2013-2015)\end{array}$ & $\begin{array}{l}\text { Post-intensivist period } \\
\text { (2015-2017) }\end{array}$ & $P$ value \\
\hline Number of patients & 513 & 1274 & \\
\hline Age, months, mean $\pm \mathrm{SD}$ & $62.2 \pm 59.3$ & $66.1 \pm 60.1$ & $0.211 *$ \\
\hline Female gender, $\mathrm{n}(\%)$ & $256(49.9)$ & $634(49.7)$ & $0.958 * *$ \\
\hline \multicolumn{4}{|l|}{ Admission source, $\mathrm{n}(\%)$} \\
\hline $\begin{array}{l}\text { Ambulance service, } \mathrm{n}(\%) \\
\text { Inpatient service, } \mathrm{n}(\%)\end{array}$ & $\begin{array}{l}227(44.2) \\
275(53.6)\end{array}$ & $\begin{array}{l}736(57.7) \\
366(28.7)\end{array}$ & \multirow[t]{2}{*}{$<0.001 * *$} \\
\hline Post-surgical, n $(\%)$ & $11(2.1)$ & $172(13.5)$ & \\
\hline Mechanically ventilated patients, $\mathrm{n}$ & 229 & 530 & \multirow[t]{2}{*}{$0.240 * *$} \\
\hline Mechanical ventilator usage rate, $\%$ & 44.6 & 41.6 & \\
\hline Mechanical ventilation duration, days, mean $\pm \mathrm{SD}$ & $23.8 \pm 19.8$ & $7.0 \pm 5.5$ & $<0.001 *$ \\
\hline Patients underwent tracheotomy, n (\%) & $39(7.6)$ & $34(2.6)$ & $<0.001 * *$ \\
\hline Mechanical ventilator days prior to tracheotomy day, mean \pm SD & $29.2 \pm 8.8$ & $16.6 \pm 6.1$ & $<0.001 *$ \\
\hline Central venous catheter implemented patients, $\mathrm{n}(\%)$ & $156(30.4)$ & $570(44.7)$ & $<0.001 * *$ \\
\hline Central venous catheter usage rate, $\%$ & 30.4 & 44.7 & $<0.001 * *$ \\
\hline CVVHDF, n (\%) & $17(3.3)$ & $51(4.4)$ & 0.491 \\
\hline TPE, n (\%) & $5(0.9)$ & $36(2.8)$ & $<0.001 * *$ \\
\hline ECMO, n $(\%)$ & $1(0.1)$ & $13(1)$ & $<0.001 * *$ \\
\hline Nosocomial infections, $\mathrm{n}(\%)$ & $143(27.8)$ & $50(3.9)$ & $<0.001 * *$ \\
\hline Nosocomial infection rate, $\%$ & 27.8 & 3.8 & $<0.001 * *$ \\
\hline Nosocomial infection incidence density (per 1000 patient days) & 19.7 & 6.2 & $0.006 * *$ \\
\hline Ventilator associated pneumonia, $\mathrm{n}(\%)$ & $28(5.4)$ & $9(0.7)$ & $<0.001 * *$ \\
\hline Ventilator associated pneumonia rate (per 1000 ventilator days) & 5.1 & 2.4 & $<0.001 * *$ \\
\hline Length of stay, day, mean \pm SD & $14.0 \pm 18.7$ & $6.3 \pm 5.2$ & $<0.001 *$ \\
\hline PRISM score, mean & $7.6 \pm 9.1$ & $8.2 \pm 10.2$ & $0.202 *$ \\
\hline SMR & 0.9 & 0.45 & $<0.001 *$ \\
\hline Mortality rate, $\%$ & 14.2 & 7 & $<0.001 *$ \\
\hline
\end{tabular}

CVVHDF Continuous venovenous hemodiafiltration; ECMO Extracorporeal membrane oxygenation; PRISM Pediatric Risk of Mortality; SMR Standard mortality rate; TPE Therapeutic plasma exchange

*Student $\mathrm{t}$ test; **Pearson Chi-Square

reduced mortality rate 2.18 times $(95 \%$ CI $1.573-3.028$, $p<0.001)$.

General linear model was performed to predict the effect of intensivist on the length of stay in PICU, mechanical ventilator duration and mechanical ventilator duration prior to tracheotomy. Presence of intensivist reduced mechanical ventilator duration by $59 \%$, mechanical ventilator duration prior to tracheotomy by $90 \%$ and length of stay in PICU by $41.2 \%$ (Table 2).

\section{Discussion}

In the current study, the positive effect of the management of the PICU by a pediatric intensivist is demonstrated from many aspects. Number of patients followed in the PICU increased more than 2-fold (513vs. 1274). Admission source of patients changed significantly and most of the patients in the post pediatric intensivist period were accepted from other centers via emergency ambulance transport system. Number of postsurgical patients increased more than 15-times (11 vs. 172) and more than 6-times in terms of percentage $(2.1 \% v s$. $13.5 \%$ ) (Table 1). Among post-surgical patients, most of them were postoperative congenital heart disease patients who had been managed by cardiac surgeons before the pediatric intensivist's arrival. It has already been reported that management of pediatric postoperative cardiac patients by an intensivist-directed team is associated with improved outcome [7].

Gender, age and PRISM scores of patients followed in the two periods were similar. Percentage of patients mechanically ventilated were $48 \%$ and $42 \%$ in the two periods respectively. Number of mechanically ventilated patients increased more than 2-fold in the post-intensivist period in accordance with 
Table 2 Effect of the presence of intensivist on PICU outcome

\begin{tabular}{llll} 
Pre-intensivist period & Post-intensivist period & $\begin{array}{l}\text { Effect size } \\
\% \text { reduction }\end{array}$ & $P$ value \\
\hline $23.8(1-126)$ & $7.0(1-36)$ & 59.0 & $<0.001$ \\
$29.2(10-51)$ & $16.6(9-30)$ & 90 & $<0.001$ \\
$14.0(1-136)$ & $6.2(1-39)$ & 41.2 & $<0.001$ \\
\hline
\end{tabular}

Mechanical ventilation duration, mean (min-max)

Mechanical ventilator days prior to tracheotomy, mean (min-max)

Length of stay, mean (min-max)
$29.2(10-51)$
$16.6(9-30)$

PICU Pediatric intensive care unit

the increased number of admissions (229vs. 530). Duration of mechanical ventilation shortened from $23.8 \mathrm{~d}$ to $7 \mathrm{~d}$ with the arrival of the intensivist. Presence of the intensivist reduced the mechanical ventilation duration by $59 \%$ (Table 2 ). Reduction of the mechanical ventilation duration is important as it is associated with complications such as ventilator associated pneumonia (VAP), subglottic stenosis and tolerance to sedative agents $[4,8-10]$. Patients could be extubated more quickly as a result of more efficient use of mechanical ventilator by the pediatric intensivist. This situation resulted in a decrease in the number and rate of VAP in the PICU (5.1 vs. 2.4).

Extubation failure necessitated tracheotomy for some patients. Percentage of patients who underwent tracheotomy was $17 \%$ and $6.4 \%$ in the pre- and post-pediatric intensivist periods respectively, reflecting an increased extubation success. Mean mechanical ventilator duration prior to tracheotomy was $29.2 \mathrm{~d}$ in the pre-intensivist period. Presence of intensivist reduced the mechanical ventilation duration prior to tracheotomy by $90 \%$ (Table 2). Timing of tracheotomy is important in prolonged mechanically ventilated patients because tracheotomy facilitates separation from the mechanical ventilation and discharge from the PICU [11].

Pediatric Risk of Mortality (PRISM) scores which represent the illness severity of the patients in two groups were similar, indicating that the severity of the patients in both groups were comparable (7.6 vs. 8.2) (Table 1). Central venous catheter implementation, Continuous venovenous hemodiafiltration (CVVHDF), therapeutic plasma exchange (TPE), extracorporeal membrane oxygenation (ECMO) were more frequently used in the treatment of patients after the pediatric intensivist's arrival. Despite of increase in the invasive procedures, the rate of nosocomial infections significantly decreased in the post-pediatric intensivist period (143 vs. 50). Before the arrival of the pediatric intensivist only one venovenous ECMO was performed which was managed by cardiac surgeons; the patient, unfortunately didn't survive. In the post-pediatric intensivist period, 13 (8 venoarterial, 5 venovenous) ECMO's were performed under the supervision of the intensivist and decannulation rate reached $61.5 \%$ (8/13). ECMO program, including the education of nurses and physicians was started by the pediatric intensivist. In the pre- pediatric intensivist period, CVVHDF and TPE applications could only be performed with support of the technical staff of the supplier company. With the arrival of the pediatric intensivist, the nurse team was trained for the procedures of CVVHDF and TPE. Two senior nurses were appointed to be responsible for the CVHDF and TPE program.

Number (143vs. 50), rate (27.9vs. 3.8) and incidence (19.7 $v s$. 6.2) of nosocomial infections significantly decreased in the post-intensivist period, despite the increasing number of critically ill patients, mechanical ventilator days, invasive procedures and extracorporeal treatment sessions (Table 1). This was achieved by staff education, implementation of protocols, strict adherence to infection control methods and rational antibiotic use.

Length of PICU stay was shortened in the post-pediatric intensivist period which is similar to the previous reports [12]. Presence of intensivist reduced the length of stay in the PICU by $41.2 \%$ (Table 2). Before the pediatric intensivist, indication of PICU admission was not clear and patients with terminal diseases were admitted to the PICU. This was the main underlying reason for the prolonged PICU stay and higher rate of nosocomial infections and misusage of the valuable PICU beds. Prolonged mechanical ventilator duration, higher percentage of extubation failure, prolonged mechanical ventilator duration prior to tracheotomy are also consistent with all factors mentioned above.

Mortality rate decreased from $14.2 \%$ to $7 \%$ between the pre- and post-pediatric intensivist periods. Similarly, SMR decreased from 0.9 to 0.45 . Presence of the intensivist reduced the mortality 2.18 times (95\% CI $1.573-3.028, p<0.001$ ) (Table 1).

There are many studies showing that the presence of a pediatric intensivist reduces mortality in the PICU [1, 13, 14]. SMR calculation is more reliable than crude mortality rate as an indicator for assessment of quality of medical care in PICUs and presence of a pediatric intensivist is definitely associated with decreased SMR [12]. SMR reduction in the post-pediatric intensivist period confirms that the presence of an intensivist improves outcome (Table 1). This well-known fact is confirmed by the current study conducted in a middleincome country. 
It is important to emphasize that personnel staffing, structure and technological infrastructure of PICU were same over the course of the study. The only variable that changed in the intensive care unit was the management of the team by the pediatric intensivist. When the pediatric intensivist attended the PICU, the mortality rate decreased to $7 \%$, which is an acceptable mortality rate for a middle-income country. PICU mortality rate has been reported as $2.9 \%$ and $5.6 \%$ in United States and Europe respectively $[15,16]$.

Although the hospital where the pediatric intensivist started to work is already a tertiary reference hospital, the change in the working system in the PICU caused some systematical/organizational problems. At the beginning, decision of not admitting the terminal patients from inpatient services to PICU was questioned by the heads of other departments and the hospital administration. All the patients who were not at terminal stage and have deteriorated in other departments were transferred to PICU and treated at PICU under the responsibility of the pediatric intensivist. This situation increased the motivation of other departments to work with PICU. Administrative officials were convinced by informing them regularly about the changes in the system and updating them about the prognosis of patients in the PICU.

This study investigated the effect of only one certified intensivist on the outcomes of PICU. This is not the ideal working system for the PICU and it has been suggested previously in the literature that intensivist in-house coverage $24 \mathrm{~h}$ each day is the best way to care for critically-ill children [14]. It is not possible to provide $100 \%$ coverage of PICU beds by intensivists in our country today due to the lack of educated pediatric intensivists. It has been previously reported that the ratio of the number of pediatric intensivists to PICU beds is $1: 31.7$ in Turkey [5] while this ratio is $1: 2-1: 4.5$ in United States, 1:3-1:5 in Australia, and 1:1.2-1:1.6 in Europe [17]. This study evidently showed that the management of PICU beds by an intensivist constitutes a remarkable positive effect on PICU outcomes in many aspects. Although it is not one of the targets of this study, it is obvious that all these mentioned aspects above also influence the high costs of the intensive care.

\section{Conclusions}

In summary, this study showed that management of the PICU beds by a pediatric intensivist increased the number of PICU hospitalizations, ensured care for the true critical care patients with more intensive therapies, decreased the length of stay, decreased the number and the rate of nosocomial infections and decreased the mortality rate.
As a conclusion, what transforms a unit full of critically ill patients to an intensive care unit is a dedicated intensivist. The current study demonstrates that the intensivist is the crucial component of PICUs. "All ICUs should be covered by the intensivists" phrase still stands as a primary mission for the low- and middle-income countries.

Acknowledgments The authors thank Gülin Gökcen Kesici for statistical analysis. The authors thank Seval Altunkeser, the chief nurse of the PICU during the study period, for dedicated support in patient care.

Authors' Contribution SK and BB collected the data, wrote and reviewed the manuscript. BB is the guarantor for this paper.

\section{Compliance with Ethical Standards}

Conflict of Interest None.

\section{References}

1. Pollack MM, Katz RW, Ruttimann UE, Getson PR. Improving the outcome and efficiency of intensive care: the impact of an intensivist. Crit Care Med. 1988;16:11-7.

2. Pollack MM, Cuerdon TT, Patel KM, Ruttimann UE, Getson PR, Levetown M. Impact of quality-of-care factors on pediatric intensive care unit mortality. JAMA. 1994;272:941-6.

3. Wallace DJ, Angus DC, Barnato AE, Kramer AA, Kahn JM. Nighttime intensivist staffing and mortality among critically ill patients. N Engl J Med. 2012;366:2093-101.

4. Nishisaki A, Pines JM, Lin R, et al. The impact of 24-hr, in-hospital pediatric critical care attending physician presence on process of care and patient outcomes. Crit Care Med. 2012;40:2190-5.

5. Bayrakci B, Kesici S, Kendirli T, et al. Evaluation report of pediatric intensive care units in Turkey. Turk J Med Sci. 2014;44:107386.

6. Pollack MM, Patel KM, Ruttimann UE. PRISM III: an updated pediatric risk of mortality score. Crit Care Med. 1996;24:743-52.

7. Mayo E, Helman J, Siddappa R, Tosi L, Rotta A. An intensivistdirected multidisciplinary pediatric cardiac critical care team model is associated with improved outcomes following pediatric cardiac surgery. Crit Care Med. 2010;38:U7-U.

8. Principi T, Fraser DD, Morrison GC, et al. Complications of mechanical ventilation in the pediatric population. Pediatr Pulmonol. 2011;46:452-7.

9. Bigham MT, Amato R, Bondurrant P, et al. Ventilator-associated pneumonia in the pediatric intensive care unit: characterizing the problem and implementing a sustainable solution. J Pediatr. 2009; $154: 582-7 \mathrm{e} 2$.

10. Deeter KH, King MA, Ridling D, et al. Successful implementation of a pediatric sedation protocol for mechanically ventilated patients. Crit Care Med. 2011;39:683-8.

11. Ertugrul I, Kesici S, Bayrakci B, Unal OF. Tracheostomy in pediatric intensive care unit: when and where? Iran J Pediatr. 2016;26: e2283.

12. Goh AY, Lum LC, Abdel-Latif ME. Impact of 24 hour critical care physician staffing on case-mix adjusted mortality in paediatric intensive care. Lancet. 2001;357:445-6. 
13. Manthous CA, Amoateng-Adjepong Y, Al-Kharrat T, et al. Effects of a medical intensivist on patient care in a community teaching hospital. Mayo Clin Proc. 1997;72:391-9.

14. Tenner PA, Dibrell H, Taylor RP. Improved survival with hospitalists in a pediatric intensive care unit. Crit Care Med. 2003;31:847-52.

15. Randolph AG, Gonzales CA, Cortellini L, Yeh TS. Growth of pediatric intensive care units in the United States from 1995 to 2001. J Pediatr. 2004;144:792-8.
16. Nipshagen MD, Polderman KH, DeVictor D, Gemke RJ. Pediatric intensive care: result of a European survey. Intens Care Med. 2002;28:1797-803.

17. Ferdinande P; Members of the Task Force of the European Society of Intensive Care Medicine. Recommendations on minimal requirements for Intensive Care Departments. Intens Care Med. 1997;23: 226-32.

Publisher's Note Springer Nature remains neutral with regard to jurisdictional claims in published maps and institutional affiliations. 